\title{
The NEW ENGLAND JOURNAL of MEDICINE
}

\section{A Comparison of Outcomes with Angiotensin-Converting-Enzyme Inhibitors and Diuretics for Hypertension in the Elderly}

\author{
Lindon M.H. Wing, M.B., B.S., Christopher M. Reid, Ph.D., Philip Ryan, M.B., B.S., Lawrence J. Beilin, M.D., \\ Mark A. Brown, M.B., B.S., M.D., Garry L.R. Jennings, M.D., Colin I. Johnston, M.B., B.S., John J. McNeil, M.B., B.S., \\ Graham J. Macdonald, M.D., John E. Marley, M.D., M.B., Ch.B., Trefor O. Morgan, M.B., B.S., \\ and Malcolm J. West, M.B., B.S., for the Second Australian National Blood Pressure Study Group*
}

ABSTRACT

BACKGROUND

Treatment of hypertension with diuretics, beta-blockers, or both leads to improved outcomes. It has been postulated that agents that inhibit the renin-angiotensin system confer benefit beyond the reduction of blood pressure alone. We compared the outcomes in older subjects with hypertension who were treated with angiotensin-convertingenzyme (ACE) inhibitors with the outcomes in those treated with diuretic agents.

\section{METHODS}

We conducted a prospective, randomized, open-label study with blinded assessment of end points in 6083 subjects with hypertension who were 65 to 84 years of age and received health care at 1594 family practices. Subjects were followed for a median of 4.1 years, and the total numbers of cardiovascular events in the two treatment groups were compared with the use of multivariate proportional-hazards models.

RESULTS

At base line, the treatment groups were well matched in terms of age, sex, and blood pressure. By the end of the study, blood pressure had decreased to a similar extent in both groups (a decrease of $26 / 12 \mathrm{~mm} \mathrm{Hg}$ ). There were 695 cardiovascular events or deaths from any cause in the ACE-inhibitor group (56.1 per 1000 patient-years) and 736 cardiovascular events or deaths from any cause in the diuretic group (59.8 per 1000 patientyears; the hazard ratio for a cardiovascular event or death with ACE-inhibitor treatment was 0.89 [ 95 percent confidence interval, 0.79 to 1.00 ]; $\mathrm{P}=0.05$ ). Among male subjects, the hazard ratio was 0.83 ( 95 percent confidence interval, 0.71 to $0.97 ; \mathrm{P}=0.02$ ); among female subjects, the hazard ratio was 1.00 (95 percent confidence interval, 0.83 to 1.21; $\mathrm{P}=0.98$ ); the $\mathrm{P}$ value for the interaction between sex and treatment-group assignment was 0.15 . The rates of nonfatal cardiovascular events and myocardial infarctions decreased with ACE-inhibitor treatment, whereas a similar number of strokes occurred in each group (although there were more fatal strokes in the ACE-inhibitor group).

CONCLUSIONS

Initiation of antihypertensive treatment involving ACE inhibitors in older subjects, particularly men, appears to lead to better outcomes than treatment with diuretic agents, despite similar reductions of blood pressure.
From the School of Medicine, Flinders University, Adelaide (L.M.H.W.); the Baker Heart Research Institute, Melbourne (C.M.R., G.L.R.J., C.I.J.); the Department of Public Health, University of Adelaide, Adelaide (P.R.); the Department of Medicine, University of Western Australia, Perth (L.J.B.); the Department of Nephrology, University of New South Wales, Sydney (M.A.B.); the Department of Epidemiology and Preventive Medicine, Monash University, Melbourne (J.J.M.); Merck Sharp \& Dohme, Sydney (G.J.M.); the Faculty of Health, University of Newcastle, Newcastle (J.E.M.); the Department of Physiology, University of Melbourne, Melbourne (T.O.M.); and the Department of Medicine, University of Queensland, Brisbane (M.J.W.) - all in Australia. Address reprint requests to Dr. Reid at the Baker Heart Research Institute, P.O. Box 6492, St. Kilda Rd. Central, Melbourne, VIC 8008, Australia, or at chris.reid@baker. edu.au.

*Investigators in the Second Australian National Blood Pressure Study (ANBP2) are listed in the Appendix.

N EnglJ Med 2003;348:583-92.

Copyright $\odot 2003$ Massachusetts Medical Society. 
P LACEBO-CONTROLLED STUDIES OF THE drug treatment of mild-to-moderate hypertension have demonstrated that the reduction of blood pressure is associated with a reduced risk of cardiovascular events and death. ${ }^{1-7}$ This benefit was first shown with diuretics, beta-blockers, or both as initial therapy. ${ }^{1-6}$ Since those studies were conducted, newer classes of antihypertensive agents, including angiotensin-converting-enzyme (ACE) inhibitors, calcium-channel antagonists, and angiotensin II antagonists, have become widely accepted into practice. When our study began, no data were available indicating whether therapy involving these newer agents would have the same benefit in persons with hypertension. However, evidence of a benefit of treatment with ACE inhibitors in the improvement of impaired cardiac function ${ }^{8-10}$ suggested that they conferred additional benefit beyond their ability to lower blood pressure, possibly because of effects on independent cardiovascular risk factors. ${ }^{11-13}$ It had earlier been suggested that excessive activity of the renin-angiotensin system had deleterious cardiovascular effects beyond its influence on blood pressure. ${ }^{14}$

During the past three to four years, results have been published of studies evaluating differences between regimens based on conventional agents and regimens based on newer drugs in terms of outcomes in hypertensive subjects. ${ }^{15-18}$ None of the studies involving ACE inhibitors or calcium-channel antagonists has yet demonstrated a clear difference in outcome between treatment groups. ${ }^{19}$ The recent Heart Outcomes Prevention Evaluation (HOPE) study reported that ACE inhibitors confer a benefit in terms of outcome despite the fact that they result in little or no change in blood pressure in high-risk subjects. ${ }^{20}$ Further supportive evidence comes from the Losartan Intervention for Endpoint Reduction (LIFE) study, which demonstrated that antihypertensive therapy with the angiotensin II antagonist losartan prevented more cardiovascular events and deaths than did therapy with the beta-blocker atenolol, which led to a similar reduction in blood pressure. ${ }^{21}$

Our study was undertaken to address the question of possible regimen-specific benefit with respect to the outcome of the treatment of hypertension. We investigated whether there was any difference in outcome between hypertensive subjects who are actively treated with an ACE-inhibitor-based regimen and those treated with a diuretic-based regimen. Unlike many previous studies, our study enrolled older subjects with hypertension who had had few previous cardiovascular events. The study was conducted at family practices throughout Australia and thus reflects routine clinical practice for the management of hypertension.

\section{METHODS}

\section{STUDY DESIGN}

The study design and recruitment strategies have been published previously. ${ }^{22-24}$ In brief, the study was conducted at 1594 family medical practices throughout Australia, with the use of a prospective, randomized, open-label design, with blinded assessments of end points. ${ }^{25}$

At screening, blood pressure was measured by trained study nurses using a mercury sphygmomanometer in all eligible subjects 65 to 84 years of age. ${ }^{26}$ Suitable subjects had two subsequent studyentry visits at least one week apart. In subjects who were taking antihypertensive drugs, medication was discontinued under medical supervision. Subjects were required to be free of antihypertensive drugs for at least one week before the study-entry visits.

\section{CRITERIA FOR INCLUSION AND EXCLUSION}

Criteria for inclusion in the study were an average systolic blood pressure, measured at the two studyentry visits while the subject was sitting, of at least $160 \mathrm{~mm} \mathrm{Hg}$ or an average diastolic blood pressure of at least $90 \mathrm{~mm} \mathrm{Hg}$ (if the systolic blood pressure was at least $140 \mathrm{~mm} \mathrm{Hg}$ ); the absence of recent cardiovascular events (within the previous six months); and willingness to give informed consent. Criteria for exclusion included any life-threatening illness, contraindication to an ACE inhibitor or diuretic, a plasma creatinine concentration of more than 2.5 mg per deciliter (221 $\mu \mathrm{mol}$ per liter), malignant hypertension, or dementia. Subjects were randomly assigned centrally by telephone to either ACE-inhibitor-based or diuretic-based treatment. Randomization began in April 1995 and was completed in June 1998.

\section{GOALS AND TREATMENTS}

Family practitioners were responsible for the management of antihypertensive therapy, which was to conform to the randomized treatment assignment and the study's blood-pressure goals. The guidelines were based on the aim of achieving a reduction of the systolic blood pressure by at least $20 \mathrm{~mm} \mathrm{Hg}$ to less than $160 \mathrm{~mm} \mathrm{Hg}$, with a further reduction to 
less than $140 \mathrm{~mm} \mathrm{Hg}$ if tolerated, and a reduction of the diastolic blood pressure by at least $10 \mathrm{~mm} \mathrm{Hg}$ to less than $90 \mathrm{~mm} \mathrm{Hg}$, with a further reduction to less than $80 \mathrm{~mm} \mathrm{Hg}$ if tolerated. ${ }^{24}$ The ACE inhibitor enalapril and the diuretic hydrochlorothiazide were recommended as initial therapy; however, the choice of the specific agent and dose was made by the family practitioner.

To achieve the blood-pressure goals, the addition of beta-blockers, calcium-channel blockers, and alpha-blockers was recommended in both groups. ${ }^{24}$ Blood pressure was recorded annually by study nurses and at each patient visit by the general practitioner, using routine mercury sphygmomanometry. Case records, hospital notes, and death certificates were reviewed by study nurses for documentation of end points every six months throughout the study.

\section{END POINTS}

The primary end point was all cardiovascular events or death from any cause. Both initial and subsequent fatal and nonfatal cardiovascular events were included. Cause-specific cardiovascular events included the following: coronary events, including myocardial infarction, sudden or rapid death from cardiac causes, other deaths from coronary causes, or coronary events associated with therapeutic procedures involving the coronary arteries; other cardiovascular events, including heart failure, acute occlusion of a major feeding artery in any vascular bed other than cerebral or coronary, death from noncoronary cardiac causes, dissecting or ruptured aortic aneurysm, or death from vascular causes; and cerebrovascular events, including stroke and transient ischemic attacks. An end-point committee whose members were unaware of the treatmentgroup assignments adjudicated all potential end points.

\section{APPROVAL, SUPPORT, AND CONDUCT OF THE STUDY}

The protocol was approved by the ethics committee of the Royal Australian College of General Practitioners and conducted in accordance with the Helsinki Declaration. ${ }^{27}$ All subjects gave written informed consent. The study is a project of the High Blood Pressure Research Council of Australia that was initiated, designed, and conducted by the investigators. Although it was funded by a joint venture of the Commonwealth Government of Australia, the National Health and Medical Research Council, Merck Sharp \& Dohme, and academic institu- tions, ${ }^{28}$ all data analysis and writing were performed independently by the publications committee, without the involvement of representatives of Merck Sharp \& Dohme.

\section{STATISTICAL ANALYSIS}

Three thousand subjects were required in each group for the study to achieve a power of 90 percent to detect a 25 percent difference between the treatment groups in the rate of cardiovascular events during a five-year period, assuming a rate of 21 events per 1000 person-years in the diuretic group ${ }^{4}$ and allowing for a 15 percent loss to follow-up. The management committee decided to stop the trial because the observed total number of events had well exceeded the number required on the basis of the estimate of sample size and because resources became limited as the result of an extension of the recruitment period. No comparison of the treatment groups in terms of data on outcomes was performed before the study was terminated.

Cox regression was used to model multiple times to events, with the treatment-group assignment as the principal predictor. ${ }^{29,30}$ An event was defined as any cardiovascular event or death from any cause. Robust estimates of variance were used to allow for the clustering of subjects according to practitioner, and potential confounding by risk factors was explored by analysts who were unaware of changes in $P$ values or of the direction of changes in estimates. ${ }^{31}$ Only age and sex changed estimates substantially and were therefore adjusted for in the model. Cumulative hazard functions were plotted to check for proportional hazards. Simulation methods were used to validate estimates of the hazard ratios and confidence intervals.

The two primary comparisons (all events and any first events) were tested at the 0.05 level of significance. Hazard ratios with 95 percent confidence intervals and two-sided P values are presented. Hazard ratios from secondary comparisons of causespecific first events and subgroups defined according to sex are also shown with 95 percent confidence intervals and P values unadjusted for multiple testing, in order to facilitate comparisons with results from other studies. However, the significance of these secondary results should be judged cautiously. ${ }^{32}$ The number needed to treat to avoid one additional event was estimated from survival functions based on the proportional-hazards model. ${ }^{33}$ All results are based on intention-to-treat analyses. 


\section{RESULTS}

\section{STUDY SUBJECTS}

A total of 54,288 subjects presented for the initial screening visit. Fifty-eight percent $(31,255)$ either were currently being treated for hypertension (25,926 subjects [48 percent]) or had untreated blood pressure in the range specified by the eligibility criteria ( 5329 subjects [10 percent]). A total of 8316 subjects ( 4682 previously treated subjects and 3634 untreated subjects) had study-entry visits, and
6083 subjects ( 95 percent of whom were white) were subsequently randomly assigned to the ACE-inhibitor group (3044 subjects) or the diuretic group (3039 subjects) (Fig. 1). Subjects were recruited over a 3-year period and were followed for a median of 4.1 years, for a total of 24,702 patient-years of observation. As indicated in Figure 1, all subjects who underwent randomization were included in the final analysis. For subjects who were lost to followup monitoring, we used the last available data; vital status was ascertained for all but two subjects.

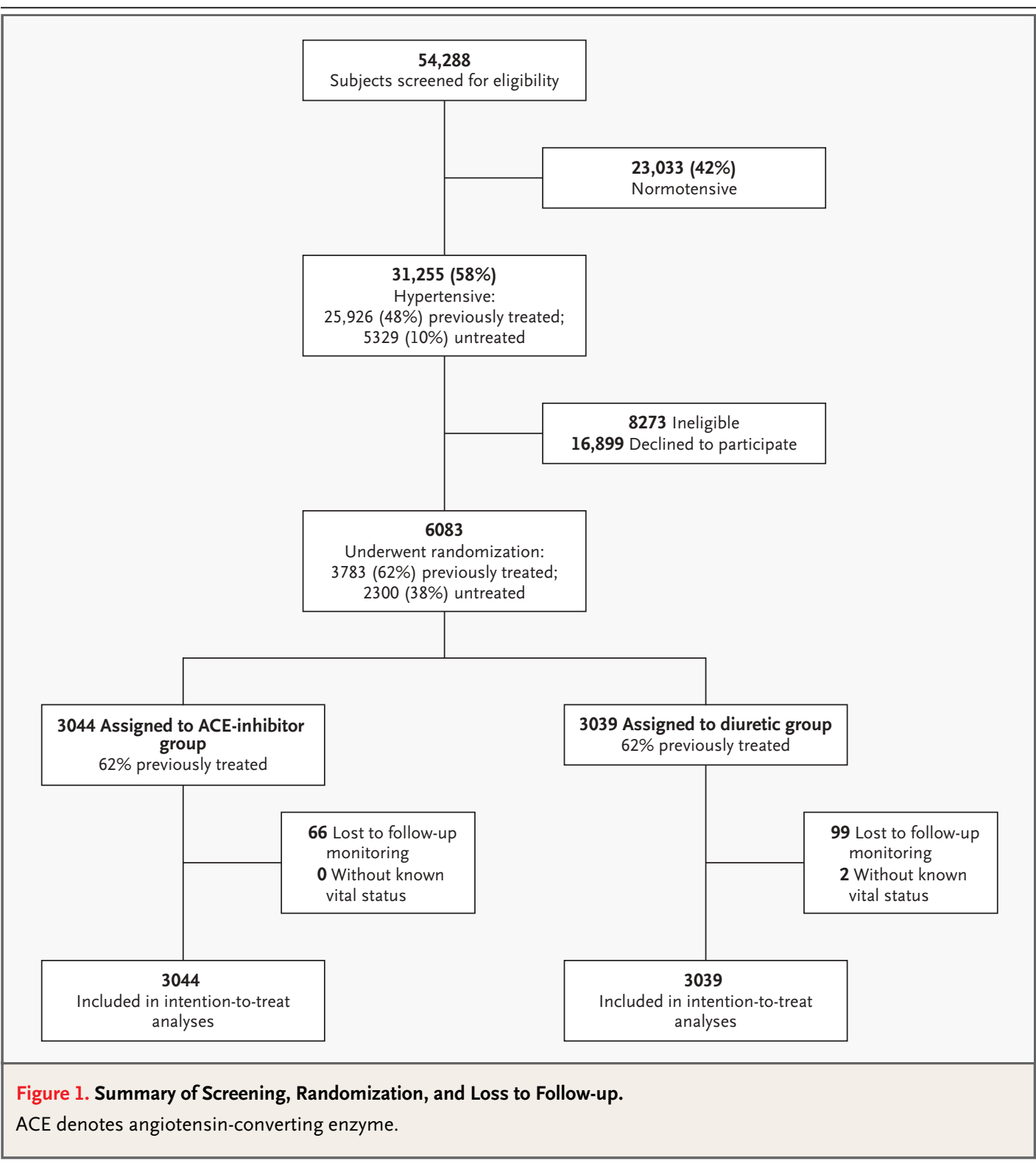




\section{BASE-LINE DATA}

The two treatment groups were similar in terms of sex, age, blood pressure, body-mass index (the weight in kilograms divided by the square of the height in meters), plasma cholesterol concentration, tobacco and alcohol use, the level of physical activity, and the extent of previous treatment with antihypertensive drugs (Table 1). Eight percent of subjects had previously had a coronary event, 5 percent had previous cerebrovascular disease, and 7 percent had received a diagnosis of diabetes. Mean $( \pm \mathrm{SD})$ systolic blood pressure at entry was $168 \pm 13$ $\mathrm{mm} \mathrm{Hg}$; mean diastolic blood pressure at entry was $91 \pm 8 \mathrm{~mm} \mathrm{Hg}$.

\section{DRUG TREATMENTS}

At randomization, 83 percent of subjects in both treatment groups began to receive the treatment to which they were assigned, with approximately 15 to 16 percent of subjects not receiving immediate treatment. At the end of the study, 58 percent of subjects randomly assigned to the ACE-inhibitor group and 62 percent of those assigned to the diuretic group were still receiving the assigned treatment. Sixty-five percent of the subjects in the ACE-inhibitor group and 67 percent of those in the diuretic group were receiving monotherapy; 6 percent of the subjects in the ACE-inhibitor group and 5 percent of those in the diuretic group were receiving three or more agents. Concomitant antihypertensive medications (sometimes used in combination) included calcium-channel blockers (in 22.9 percent of subjects in the ACE-inhibitor group and 24.9 percent of subjects in the diuretic group), beta-blockers (10.8 percent and 13.7 percent, respectively), and angiotensin-receptor blockers (14.0 percent and 12.4 percent, respectively).

\section{BLOOD PRESSURE}

At year 1, blood pressure had decreased by 20/9 $\mathrm{mm} \mathrm{Hg}$ in the ACE-inhibitor group and $22 / 9 \mathrm{~mm} \mathrm{Hg}$ in the diuretic group; at year 2 , it had decreased by 23/10 mm Hg in the ACE-inhibitor group and 24/10 $\mathrm{mm} \mathrm{Hg}$ in the diuretic group; and at year 5, it had decreased by 26/12 $\mathrm{mm} \mathrm{Hg}$ in both groups (Fig. 2). These were significant and clinically relevant reductions from base-line values. There were no differences between the groups in the change in diastolic blood pressure at any time point. The pattern of blood-pressure reduction with the two treatments was similar among men and among women.

\section{OUTCOMES}

The overall rates of all cardiovascular events or death in the two treatment groups are shown in Table 2. The hazard ratio for all cardiovascular events or death from any cause among subjects in the ACE-inhibitor group as compared with those in the diuretic group was 0.89 (95 percent confidence interval, 0.79 to $1.00 ; \mathrm{P}=0.05)$; in other words, there was an 11 percent reduction in the total burden of

\begin{tabular}{|c|c|c|c|}
\hline Characteristic & $\begin{array}{l}\text { ACE-Inhibitor Group } \\
\qquad(\mathrm{N}=3044)\end{array}$ & $\begin{array}{l}\text { Diuretic Group } \\
\qquad(\mathrm{N}=3039)\end{array}$ & $\begin{array}{l}\text { All Subjects } \\
(\mathrm{N}=6083)\end{array}$ \\
\hline \multicolumn{4}{|l|}{ Sex (\%) } \\
\hline Male & 50 & 48 & 49 \\
\hline Female & 50 & 52 & 51 \\
\hline \multicolumn{4}{|l|}{ Age } \\
\hline Mean (yr) & 72.0 & 71.9 & 71.9 \\
\hline $65-74$ yr (\%) & 70 & 70 & 70 \\
\hline $75-84$ yr (\%) & 30 & 30 & 30 \\
\hline \multicolumn{4}{|l|}{$\begin{array}{l}\text { Blood pressure at random- } \\
\text { ization }(\mathrm{mm} \mathrm{Hg})\end{array}$} \\
\hline Systolic & $167 \pm 13$ & $168 \pm 13$ & $168 \pm 13$ \\
\hline Diastolic & $91 \pm 8$ & $91 \pm 8$ & $91 \pm 8$ \\
\hline \multicolumn{4}{|l|}{ Blood-pressure grade (\%) } \\
\hline 1 & 20 & 18 & 19 \\
\hline 2 & 65 & 66 & 66 \\
\hline 3 & 15 & 15 & 15 \\
\hline Previously treated (\%) & 62 & 62 & 62 \\
\hline Body-mass index ${ }^{\dagger}$ & $27 \pm 4$ & $27 \pm 4$ & $27 \pm 4$ \\
\hline \multicolumn{4}{|l|}{ Smoking status (\%) } \\
\hline Current & 7 & 7 & 7 \\
\hline Previous & 46 & 45 & 45 \\
\hline \multicolumn{4}{|l|}{ Alcohol use (\%) } \\
\hline Current & 74 & 72 & 73 \\
\hline Previous & 6 & 7 & 6 \\
\hline Physically active (\%) & 78 & 76 & 77 \\
\hline Coronary heart disease (\%) & 8 & 8 & 8 \\
\hline Cerebrovascular disease (\%) & 5 & 4 & 5 \\
\hline Diabetes mellitus (\%) & 8 & 7 & 7 \\
\hline Hypercholesterolemia (\%) & 38 & 36 & 37 \\
\hline $\begin{array}{l}\text { Receiving lipid-lowering } \\
\text { drugs }\end{array}$ & 13 & 13 & 13 \\
\hline
\end{tabular}

* Plus-minus values are means \pm SD. Coronary heart disease included myocardial infarction, angina, coronary-artery bypass grafting, and percutaneous transluminal coronary angioplasty; cerebrovascular disease included stroke and transient ischemic attack. The blood-pressure grade was according to the criteria of the World Health Organization and the International Society of Hypertension. ${ }^{31}$ Because of rounding, not all percentages total 100 . ACE denotes angiotensin-converting enzyme. $\dagger$ The body-mass index is the weight in kilograms divided by the square of the height in meters. 


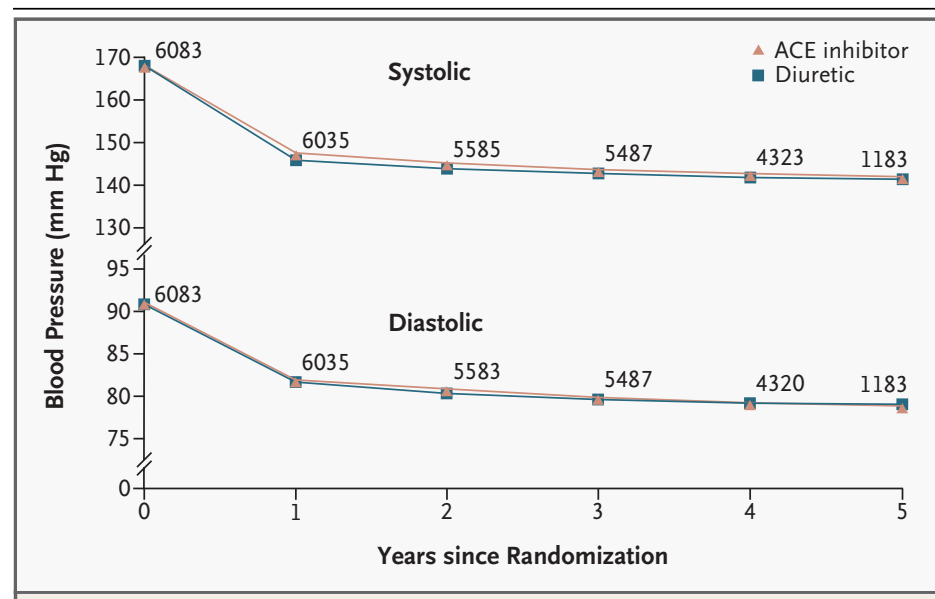

Figure 2. Systolic and Diastolic Blood Pressure after Randomization.

The numbers above the curves indicate the numbers of subjects whose blood pressure was measured. ACE denotes angiotensin-converting enzyme. cardiovascular events or death from any cause. The difference between treatment groups appeared early and remained consistent throughout the duration of the study. From a clinical perspective, 32 subjects of either sex in this age group or 23 men would need to be given ACE-inhibitor-based therapy in order to prevent one additional first cardiovascular event or death within the first five years after treatment began.

There were almost twice as many events in male subjects (907 events) as in female subjects (524 events). The beneficial effects of ACE-inhibitor treatment were more evident in male subjects, among whom there was a 17 percent reduction in the rates of both all cardiovascular events and first cardiovascular events (hazard ratio for both end points, 0.83 [ 95 percent confidence interval, 0.71 to 0.97]; $P=0.02$ ) (Fig. 3). Among female subjects, the hazard ratio for all cardiovascular events and first cardiovascular events was 1.00 (95 percent confidence interval for all events, 0.83 to $1.21 ; 95$ percent confidence interval for first events, 0.83 to 1.20 ;

\begin{tabular}{|c|c|c|c|c|c|c|}
\hline \multirow[t]{2}{*}{ Event } & \multicolumn{2}{|c|}{$\begin{array}{l}\text { ACE-Inhibitor Group } \\
(\mathrm{N}=3044)\end{array}$} & \multicolumn{2}{|c|}{$\begin{array}{l}\text { Diuretic Group } \\
\qquad(\mathrm{N}=3039)\end{array}$} & \multirow[t]{2}{*}{$\begin{array}{l}\text { Hazard Ratio } \\
(95 \% \mathrm{Cl})\end{array}$} & \multirow[t]{2}{*}{$\begin{array}{c}P \\
\text { Value }\end{array}$} \\
\hline & $\begin{array}{l}\text { No. of } \\
\text { Events }\end{array}$ & $\begin{array}{l}\text { Rate per } 1000 \\
\text { Patient-yr }\end{array}$ & $\begin{array}{l}\text { No. of } \\
\text { Events }\end{array}$ & $\begin{array}{l}\text { Rate per } 1000 \\
\text { Patient-yr }\end{array}$ & & \\
\hline \multicolumn{7}{|l|}{ Primary end points } \\
\hline $\begin{array}{l}\text { All cardiovascular events or death from } \\
\text { any cause }\end{array}$ & 695 & 56.1 & 736 & 59.8 & $0.89(0.79-1.00)$ & 0.05 \\
\hline $\begin{array}{l}\text { First cardiovascular event or death from } \\
\text { any cause }\end{array}$ & 490 & 41.9 & 529 & 45.7 & $0.89(0.79-1.01)$ & 0.06 \\
\hline Death from any cause & 195 & 15.7 & 210 & 17.1 & $0.90(0.75-1.09)$ & 0.27 \\
\hline \multicolumn{7}{|l|}{ Cause-specific first events } \\
\hline First cardiovascular event $\uparrow$ & 394 & 33.7 & 429 & 37.1 & $0.88(0.77-1.01)$ & 0.07 \\
\hline Coronary event & 173 & 14.3 & 195 & 16.2 & $0.86(0.70-1.06)$ & 0.16 \\
\hline Myocardial infarction & 58 & 4.7 & 82 & 6.7 & $0.68(0.47-0.98)$ & 0.04 \\
\hline Other cardiovascular event & 134 & 11.0 & 144 & 11.9 & $0.90(0.71-1.14)$ & 0.36 \\
\hline Heart failure & 69 & 5.6 & 78 & 6.4 & $0.85(0.62-1.18)$ & 0.33 \\
\hline Cerebrovascular event & 152 & 12.5 & 163 & 13.6 & $0.90(0.73-1.12)$ & 0.35 \\
\hline Stroke & 112 & 9.2 & 107 & 8.8 & $1.02(0.78-1.33)$ & 0.91 \\
\hline
\end{tabular}

* Hazard ratios are for the event in the group assigned to angiotensin-converting-enzyme (ACE) inhibitors as compared with the diuretic group and are adjusted for age and sex. $\mathrm{Cl}$ denotes confidence interval.

$\uparrow$ Myocardial infarction is a subcategory of coronary events; heart failure is a subcategory of other cardiovascular events; and stroke is a subcategory of cerebrovascular events. Patients were counted once for each type of first cardiovascular event they had, but patients who had more than one type of event were counted only once for the overall category of first cardiovascular event. 


\begin{tabular}{|c|c|c|c|c|}
\hline \multicolumn{5}{|l|}{ All Subjects } \\
\hline & \multirow[b]{2}{*}{ Hazard Ratio $(95 \% \mathrm{Cl})$} & \multirow[b]{2}{*}{$P$ Value } & ACE Inhibitors Superior & Diuretics Superior \\
\hline End Point & & & $0.2 \quad 1.0$ & 5.0 \\
\hline All cardiovascular events or death from any cause & $0.89(0.79-1.00)$ & 0.05 & $\mathrm{H}$ & \\
\hline First cardiovascular event or death from any cause & $0.89(0.79-1.01)$ & 0.06 & 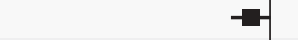 & \\
\hline Death from any cause & $0.90(0.75-1.09)$ & 0.27 & $\rightarrow$ & \\
\hline \multicolumn{5}{|l|}{ Male Subjects } \\
\hline & & & ACE Inhibitors Superior & Diuretics Superior \\
\hline End Point & Hazard Ratio (95\% Cl) & P Value & $0.2 \quad 1.0$ & 5.0 \\
\hline All cardiovascular events or death from any cause & $0.83(0.71-0.97)$ & 0.02 & $\rightarrow-$ & \\
\hline First cardiovascular event or death from any cause & $0.83(0.71-0.97)$ & 0.02 & $\rightarrow-$ & \\
\hline Death from any cause & $0.83(0.66-1.06)$ & 0.14 & $\longrightarrow$ & \\
\hline \multicolumn{5}{|l|}{ Female Subjects } \\
\hline & & & ACE Inhibitors Superior & Diuretics Superior \\
\hline End Point & Hazard Ratio (95\% Cl) & P Value & 0.2 & 5.0 \\
\hline All cardiovascular events or death from any cause & $1.00(0.83-1.21)$ & 0.98 & $\rightarrow$ & \\
\hline First cardiovascular event or death from any cause & $1.00(0.83-1.20)$ & 0.98 & $\rightarrow$ & - \\
\hline Death from any cause & $1.01(0.76-1.35)$ & 0.94 & $t^{t}$ & - \\
\hline \multicolumn{5}{|c|}{ Figure 3. Primary End Points among All Subjects, Male Subjects, and Female Subjects. } \\
\hline CE denotes angiotensin-converting enzyme, a & $\mathrm{Cl}$ confidence interva & & & \\
\hline
\end{tabular}

$\mathrm{P}=0.98$ for both comparisons). The $\mathrm{P}$ value for the interaction between sex and treatment-group assignment was 0.15 for all cardiovascular events or death from any cause and 0.14 for first cardiovascular events.

The hazard ratio for all first cardiovascular events in the ACE-inhibitor group as compared with the diuretic group was 0.88 (95 percent confidence interval, 0.77 to $1.01 ; \mathrm{P}=0.07)$; this ratio represents a 12 percent reduction over the study period (Table 2 ). There was no significant difference between treatments in terms of the rate of first coronary events, but there was a reduction in the rate of first myocardial infarctions in the ACE-inhibitor group: the adjusted hazard ratio was 0.68 (95 percent confidence interval, 0.47 to $0.98 ; \mathrm{P}=0.04$ ).

There was no significant difference between the two treatment groups in the rates of fatal cardiovascular or noncardiovascular events (Table 3). The rates of cause-specific fatal events did not differ significantly between the treatment groups, with the exception of the rate of fatal strokes, which was higher with ACE-inhibitor treatment (adjusted hazard ratio, 1.91 [95 percent confidence interval, 10.4 to 3.50$] ; \mathrm{P}=0.04$ ).

There was a 14 percent reduction in the rate of first nonfatal cardiovascular events with ACE-inhib- itor treatment (adjusted hazard ratio, 0.86 [95 percent confidence interval, 0.74 to 0.99$] ; \mathrm{P}=0.03$ ) and a 32 percent reduction in the rate of first nonfatal myocardial infarctions (adjusted hazard ratio, 0.68 [95 percent confidence interval, 0.47 to 0.99]; $\mathrm{P}=0.05$ ) (Table 3 ). There was no significant difference between treatments in terms of any other first nonfatal cardiovascular events. As with the main outcomes of the study, differences between treatment groups in cause-specific fatal and nonfatal events were observed only among male subjects.

\section{DISCUSSION}

Our study has demonstrated that outcomes are better when hypertension in the elderly is treated with an ACE inhibitor than when it is treated with a diuretic agent, with the difference being observed primarily among male subjects. In contrast to other recent trials in the elderly, the subjects in this trial were relatively healthy and active and, overall, had few previous cardiovascular events; one would therefore expect the benefit to be smaller than that found in the other trials, but the results should be more generally applicable to elderly populations. The benefit was a reduction in the rate of total cardiovascular events or death from any cause, with a 


\begin{tabular}{|c|c|c|c|c|c|c|}
\hline \multirow[t]{2}{*}{ Event } & \multicolumn{2}{|c|}{$\begin{array}{l}\text { ACE-Inhibitor Group } \\
\qquad(\mathrm{N}=3044)\end{array}$} & \multicolumn{2}{|c|}{$\begin{array}{l}\text { Diuretic Group } \\
\qquad(\mathrm{N}=3039)\end{array}$} & \multirow[t]{2}{*}{$\begin{array}{l}\text { Hazard Ratio } \\
(95 \% \mathrm{Cl})\end{array}$} & \multirow[t]{2}{*}{$\begin{array}{c}P \\
\text { Value }\end{array}$} \\
\hline & $\begin{array}{l}\text { No. of } \\
\text { Events }\end{array}$ & $\begin{array}{l}\text { Rate per } 1000 \\
\text { Patient-yr }\end{array}$ & $\begin{array}{l}\text { No. of } \\
\text { Events }\end{array}$ & $\begin{array}{l}\text { Rate per } 1000 \\
\text { Patient-yr }\end{array}$ & & \\
\hline \multicolumn{7}{|l|}{ Fatal events } \\
\hline Cardiovascular & 84 & 6.8 & 82 & 6.7 & $0.99(0.72-1.35)$ & 0.94 \\
\hline Coronary event & 40 & 3.2 & 52 & 4.2 & $0.74(0.49-1.11)$ & 0.14 \\
\hline Myocardial infarction & 9 & 0.7 & 11 & 0.9 & $0.79(0.31-1.99)$ & 0.61 \\
\hline Other cardiovascular event & 15 & 1.2 & 15 & 1.2 & $0.95(0.46-1.96)$ & 0.89 \\
\hline Heart failure & 2 & 0.2 & 8 & 0.7 & $0.24(0.03-1.94)$ & 0.18 \\
\hline Stroke & 29 & 2.3 & 15 & 1.2 & $1.91(1.04-3.50)$ & 0.04 \\
\hline Noncardiovascular & 111 & 9.0 & 128 & 10.4 & $0.84(0.66-1.08)$ & 0.18 \\
\hline Nonfatal cardiovascular events & 338 & 28.9 & 380 & 32.8 & $0.86(0.74-0.99)$ & 0.03 \\
\hline Coronary event & 141 & 11.6 & 149 & 12.4 & $0.92(0.73-1.16)$ & 0.49 \\
\hline Myocardial infarction & 50 & 4.1 & 71 & 5.8 & $0.68(0.47-0.99)$ & 0.05 \\
\hline Other cardiovascular event & 120 & 9.9 & 137 & 11.3 & $0.84(0.66-1.07)$ & 0.17 \\
\hline Heart failure & 68 & 5.5 & 77 & 6.3 & $0.85(0.62-1.17)$ & 0.32 \\
\hline Stroke & 91 & 7.5 & 94 & 7.8 & $0.93(0.70-1.26)$ & 0.65 \\
\hline
\end{tabular}

* Myocardial infarction is a subcategory of coronary events; heart failure is a subcategory of other cardiovascular events. For nonfatal events, patients were counted once for each type of event they had, but patients who had more than one type of event were counted only once for the overall category of nonfatal cardiovascular events. Hazard ratios are for the event in the group assigned to angiotensin-converting-enzyme (ACE) inhibitors as compared with the diuretic group and are adjusted for age and sex. Cl denotes confidence interval.

particular reduction in the rate of nonfatal events. There was also a reduced likelihood of a first cardiovascular event or death.

Since we conducted the study in the familypractice setting, our results reflect the probable effects among relatively healthy elderly persons with hypertension in typical care settings. For example, 15 to 16 percent of subjects in both groups did not immediately begin receiving medication, because the family practitioner and the patient preferred to delay treatment. Faced with an elderly hypertensive patient with blood pressure just above 140/90 $\mathrm{mm} \mathrm{Hg}$ (satisfying the criteria for study entry), a primary care physician may choose not to begin treatment immediately despite established evidence of benefit. However, all but 3 to 4 percent of subjects were treated during the study. The finding that approximately 60 percent of subjects continued to receive the treatment to which they were assigned for the duration of the study is consistent with findings in other trials focused on hypertension in elderly subjects and suggests what is likely to happen in practice. $4,7,15$

Three other published studies have compared ACE-inhibitor-based therapy for hypertension with conventional treatment: the Swedish Trial in Old Patients with Hypertension-2 (STOP-2) study, ${ }^{15}$ the Captopril Prevention Project (CAPPP), ${ }^{16}$ and the United Kingdom Prospective Diabetes Study (UKPDS). ${ }^{34}$ The results of these studies are consistent with our findings, but our trial also demonstrates differences of a clinically and statistically relevant magnitude. The design of the trial, the entry criteria, the definition of end points, and the alpha error are factors that may have contributed to the differences between our findings and those of other studies. Although a prospective meta-analysis has concluded that "there were no detectable differences between randomized groups in the risks of any of the outcomes studied,"19 our study and the Antihypertensive and Lipid-Lowering Treatment to Prevent Heart Attack Trial (ALLHAT) ${ }^{35}$ will be in- 
cluded in the next cycle of this meta-analysis, which will provide a more definitive comparison of outcomes with ACE-inhibitor-based and diureticbased regimens. ${ }^{19,36,37}$

The observation in our study that the relative benefits of an ACE-inhibitor-based regimen were restricted to men is of interest but should be interpreted with caution, since it represents a post hoc analysis of the data and requires confirmation. The observation that the rate of events among male subjects was almost twice that among female subjects is highly consistent with current data on morbidity and mortality. ${ }^{38}$ Men have a higher cardiovascular risk than women, and ACE-inhibitor treatment may be of particular advantage in subjects with high cardiovascular risk because of factors that influence the atherosclerotic process, such as stability of plaque and endothelial function. ${ }^{39}$ This possibility is consistent with results from the HOPE trial showing that ACE inhibitors are beneficial in subjects with high cardiovascular risk, despite minimal change in blood pressure. ${ }^{20}$ Other possible mechanisms include the absence of any adverse effect on circulating lipids, ${ }^{12,13}$ reduction of left ventricular hypertrophy, ${ }^{11}$ greater likelihood of survival in the presence of cardiac failure, ${ }^{9}$ reduced left ventricular function, ${ }^{40}$ enhanced insulin sensitivity, ${ }^{13}$ and preservation of the glomerular filtration rate. ${ }^{41-43}$ Substudies of our study concerning ambulatory monitoring of blood pressure, left ventricular hypertrophy, and vascular compliance may provide evidence clarifying the mechanisms of the putative benefit of ACE-inhibitor therapy beyond its effect on blood pressure.
The reason for discrepant observations concerning the relation between ACE-inhibitor treatment and cause-specific end points - with a greater likelihood that a stroke will be fatal but a lower likelihood of myocardial infarction - is not obvious. An indication that the benefit of treatment does relate to the reduction of the effects of angiotensin II comes from the results of the LIFE study, ${ }^{21}$ which demonstrated a reduction in cardiovascular events or death from cardiovascular causes of 13 percent (95 percent confidence interval, 2 to 23 percent) with losartan as compared with atenolol, despite an equivalent reduction in blood pressure.

In conclusion, in elderly subjects with hypertension, particularly among male subjects, ACE-inhibitor-based therapy resulted in an outcome advantage over a diuretic-based regimen, despite similar reductions in blood pressure. This finding was observed in family practices, where most elderly persons with hypertension receive their care. The question of whether the relative benefit of beginning treatment with an ACE-inhibitor-based regimen is confined to men requires examination in large, ongoing trials.

Supported by the Australian Commonwealth Department of Health and Aging; the National Health and Medical Research Council of Australia; and Merck Sharp \& Dohme, Australia.

Dr. Wing has reported receiving grants from Merck Sharp \& Dohme. Dr. Beilin has reported receiving grants from Fisheries Research and Development Corporation. Dr. Johnston has reported receiving consulting fees and lecture support from Bristol-Myers Squibb and receiving consulting fees from Merck Sharp \& Dohme.

We are indebted to the research coordinating, nursing, and trial staff, and in particular to Kristyn Willson, biostatistician, to Helen Miles, data manager, and to Carol Bear, study administrator.

APPENDIX

The following persons participated in the Second Australian National Blood Pressure Study: Regional Coordinating Centers: M. Nelson, A. Bruce, P. Beckinsale, J. Thompson, M. McMurchie, G. Fraser, D. Gleave, V. Cope, F. DeLooze, S. Moore, C. Dibben, J. Newbury; Data Management and National Coordinating Centers: H. Miles, B. McDermott, K. Willson, C. Bear; Genetic Subcommittee: M. West, S. Harrap, C. Johnston, L. Beilin, P. Ryan, L. Wing, C. Reid; Ambulatory Blood Pressure Monitoring Subcommittee: L. Beilin, M. Brown, P. Ryan, L. Wing, C. Reid; Left Ventricular Hypertrophy Subcommittee: G. Jennings, P. Fletcher, M. Feneley, E. Dewar, L. Wing, C. Reid; Data Audit Subcommittee: J. McNeil, L. Wing, J. Marley, C. Reid; Finance Subcommittee: C. Johnston, G. Jennings, L. Wing, C. Reid; Health Economic-Quality-of-Life Subcommittee: J. Marley, J. Moss, P. Webb, P. Glasziou, F. Boyle, J. Primrose, L. Wing, C. Reid; Family Practitioner Advisory Committee: I. Steven, L. Piterman, F. De Looze, J. Dickinson, J. Gambrill, P. Joseph, C. Reid; End-Point Committee: D. Hunt, G. Donnan, L. Wing, T. Morgan; Independent Data Audit Subcommittee: J. Chalmers, J. Whitworth, S. MacMahon, C. Silagy (deceased).

The list of family-practice investigators who participated in the study can be found in Supplementary Appendix 1 (available with the complete text of this article at http://www.nejm.org).

REFERENCES

1. Veterans Administration Co-operative Study Group on Antihypertensive Agents. Effects of treatment on morbidity in hypertension. II. Results in patients with diastolic blood pressure averaging 90 through 114 mm Hg. JAMA 1970;213:1143-52.

2. The Australian therapeutic trial in mild hypertension: report by the Management Committee. Lancet 1980;1:1261-7.

3. Medical Research Council Working Party. MRC trial of treatment of mild hypertension: principal results. Br Med J (Clin Res Ed) 1985;291:97-104. treatment of hypertension in older adults: principal results. BMJ 1992;304:405-12.

5. SHEP Cooperative Research Group. Prevention of stroke by antihypertensive drug treatment in older persons with isolated systolic hypertension: final results of 
the Systolic Hypertension in the Elderly Program (SHEP). JAMA 1991;265:3255-64.

6. Dahlöf B, Lindholm LH, Hansson L, Schersten B, Ekbom T, Wester P-O. Morbidity and mortality in the Swedish Trial in Old Patients with Hypertension (STOP-Hypertension). Lancet 1991;338:1281-5.

7. Staessen JA, Fagard R, Thijs L, et al. Randomised double-blind comparison of placebo and active treatment for older patients with isolated systolic hypertension. Lancet 1997;350:757-64.

8. The CONSENSUS Trial Study Group. Effects of enalapril on mortality in severe congestive heart failure: results of the Cooperative North Scandinavian Enalapril Survival Study (CONSENSUS). N Engl J Med 1987;316:1429-35.

9. The SOLVD Investigators. Effect of enalapril on survival in patients with reduced lef ventricular ejection fraction and congestive heart failure. N Engl J Med 1991;325:293302.

10. Rutherford JD, Pfeffer MA, Moye LA, et al. Effects of captopril on ischemic event after myocardial infarction: results of the Survival and Ventricular Enlargement trial. Circulation 1994;90:1731-8.

11. Dahlöf B, Pennert K, Hansson L. Reversal of left ventricular hypertrophy in hypertensive patients: a metaanalysis of 109 treatment studies. Am J Hypertens 1992;5 95-110.

12. Weidmann P, Uehlinger D, Gerber A. Antihypertensive treatment and serum lipoproteins. J Hypertens 1985;3:297-306.

13. Pollare T, Lithell H, Berne C. A comparison of the effects of hydrochlorothiazide and captopril on glucose and lipid metabolism in patients with hypertension. $\mathrm{N}$ Engl Med 1989;321:868-73.

14. Gavras H, Brunner HR, Laragh JH. Renin and aldosterone and the pathogenesis of hypertensive vascular damage. Prog Cardiovasc Dis 1974;17:39-49.

15. Hansson L, Lindholm L, Ekbom T, et al Randomised trial of old and new antihypertensive drugs in elderly patients: cardiovascular mortality and morbidity the Swedish Trial in Old Patients with Hypertension-2 study. Lancet 1999;354:1751-6.

16. Hansson L, Lindholm LH, Niskanen L, et al. Effect of angiotensin-convertingenzyme inhibition compared with conventional therapy on cardiovascular morbidity and mortality in hypertension: the Captopril Prevention Project (CAPPP) randomised trial. Lancet 1999;353:611-6.

17. Brown MJ, Palmer CR, Castaigne A, et al. Morbidity and mortality in patients randomised to double-blind treatment with a long-acting calcium-channel blocker or diuretic in the International Nifedipine GITS study: Intervention as a Goal in Hypertension Treatment (INSIGHT). Lancet 2000 356:366-72. [Erratum, Lancet 2000;356: 514.]

18. Hansson L, Hedner T, Lund-Johansen P et al. Randomised trial of effects of calcium antagonists compared with diuretics and beta-blockers on cardiovascular morbidity and mortality in hypertension: the Nordic Diltiazem (NORDIL) study. Lancet 2000 356:359-65.

19. Blood Pressure Lowering Treatment Trialists' Collaboration. Effects of ACE inhibitors, calcium antagonists, and other blood-pressure-lowering drugs: results of prospectively designed overviews of randomised trials. Lancet 2000;356:1955-64. 20. The Heart Outcomes Prevention Evaluation Study Investigators. Effects of an angiotensin-converting-enzyme inhibitor, ramipril, on cardiovascular events in high-risk patients. N Engl J Med 2000;342:145-53. [Erratum, N Engl J Med 2000;342:748, 1376.]

21. Dahlöf B, Devereux RB, Kjeldsen SE, et al. Cardiovascular morbidity and mortality in the Lorsatan Intervention For Endpoint reduction in hypertension study (LIFE): randomised trial against atenolol. Lancet 2002;359:995-1003.

22. Reid CM, Ryan P, Nelson M, et al. General practitioner participation in the second Australian National Blood Pressure Study (ANBP2). Clin Exp Pharmacol Physiol 2001, 28:663-7.

23. Reid CM, Ryan P, Wing LMH. The 2nd Australian National Blood Pressure Study (ANBP2). In: Black HR, ed. Clinical trials in hypertension. New York: Marcel Dekker 2001:587-604.

24. Australian comparative outcome trial of angiotensin-converting enzyme inhibitorand diuretic-based treatment of hypertension in the elderly (ANBP2): objectives and protocol. Clin Exp Pharmacol Physiol 1997; 24:188-92.

25. Hansson L, Hedner T, Dahlöf B. Prospective Randomized Open Blinded Endpoint (PROBE) Study: a novel design fo intervention trials. Blood Press 1992;1:113 9.

26. British Hypertension Society. Blood pressure measurement. London: British Medical Journal, 1993.

27. Declaration of Helsinki: recommendations guiding physicians in biomedica research involving human subjects. Bull Pan Am Health Organ 1990;24:606-9.

28. Reid CM, Wing LMH, Graham DH. A new paradigm for funding cardiovascularoutcome research in general practice: the Second Australian National Blood Pressure Study. Med J Aust 1998;169:349-50.

29. Wei LJ, Lin DY, Weissfeld L. Regression analysis of multivariate incomplete failure time data by modeling marginal distributions. J Am Stat Assoc 1989;84:1065-73.

30. Li QH, Lagakos WS. Use of the Wei-LinWeissfeld method for the analysis of a recurring and a terminating event. Stat Med 1997, 16:925-40.

31. Guidelines Subcommittee. 1999 WHO International Society of Hypertension Guidelines for the Management of Hypertension. J Hypertens 1999;17:151-83.
32. Šidák Z. Rectangular confidence regions for the means of multivariate normal distributions. J Am Stat Assoc 1967;62: 626-33.

33. Altman D, Andersen PK. Calculating the number needed to treat for trials where the outcome is time to an event. BMJ 1999;319: $1492-5$.

34. UK Prospective Diabetes Study Group. Efficacy of atenolol and captopril in reducing risk of macrovascular and microvascular complications in type 2 diabetes: UKPDS 39. BMJ 1998;317:713-20.

35. Major outcomes in high-risk hypertensive patients randomized to angiotensinconverting enzyme inhibitor or calcium channel blocker vs. diuretic: the Antihypertensive and Lipid-Lowering Treatment to Prevent Heart Attack Trial (ALLHAT). JAMA 2002;288:2981-97.

36. Davis BR, Cutler JA, Gordon DJ, et al. Rationale and design for the Antihypertensive and Lipid Lowering Treatment to Prevent Heart Attack Trial (ALLHAT). Am J Hypertens 1995;9:342-60.

37. World Health Organization-International Society of Hypertension Blood Pressure Lowering Treatment Trialists' Collaboration. Protocol for prospective collaborative overviews of major randomized trials of blood-pressure-lowering treatments. J Hypertens 1998;16:127-37.

38. Australian Institute of Health and Welfare, Heart Foundation of Australia. Heart, stroke and vascular diseases - Australian facts 2001. Cardiovascular disease series no. 14. Canberra, Australia: National Heart Foundation of Australia, 2001. (AIHW cat. no. CVD 13.)

39. Hlubocka Z, Umnerova V, Heller S, et al. Circulating intercellular cell adhesion molecule-1, endothelin-1 and von Willebrand factor - markers of endothelial dysfunction in uncomplicated essential hypertension: the effect of treatment with ACE inhibitors. J Hum Hypertens 2002;16:557-62.

40. The SOLVD Investigators. Effect of enalapril on mortality and the development of heart failure in asymptomatic patients with reduced left ventricular ejection fractions. N Engl J Med 1992;327:685-91. [Erratum, N Engl J Med 1992;327:1768.]

41. Marre M, Chatellier G, Leblanc H, Guyene TT, Menard J, Passa P. Prevention of diabetic nephropathy with enalapril in normotensive diabetics with microalbuminuria. BMJ 1988;297:1092-5.

42. Mathiesen ER, Hommel E, Giese J, Parving $\mathrm{H}-\mathrm{H}$. Efficacy of captopril in postponing nephropathy in normotensive insulin dependent diabetic patients with microalbuminuria. BMJ 1991;303:81-7.

43. Lewis EJ, Hunsicker LG, Bain RP, Rohde $\mathrm{RD}$. The effect of angiotensin-convertingenzyme inhibition on diabetic nephropathy. N Engl J Med 1993;329:1456-62. [Erratum, N Engl J Med 1993;330:152.]

Copyright $@ 2003$ Massachusetts Medical Society. 